\title{
A Velha Rosa no jardim da Revolução: tensões culturais, homossexualidade e autoritarismo em Cuba
}

Jorge Luiz Teixeira Ribas ${ }^{1}$

Resumo: Este artigo explora, por meio do conto A Velha Rosa (1966) de Reinaldo Arenas, as dinâmicas socioculturais em Cuba nas décadas de 1950 e 1960, para investigar as implicações das mudanças culturais, da afirmação de novas subjetividades e sexualidades não normativas na conformação do processo revolucionário, do nacionalismo e das políticas autoritárias do regime cubano após a vitória da revolução em 1959. Tomando a literatura como fonte histórica, a hipótese é a de que o contexto de mudança social radical estimulou a possibilidade de abolir ou modificar as hierarquias sexuais, o que ensejou medidas coercitivas de fundamentação heteronormativa que reatualizaram, num grau mais severo, a exclusão política e social dos homossexuais na ilha. Com isso, busca-se problematizar a visão hegemônica da experiência revolucionária restrita à luta anti-imperialista, ao relacionar sexualidade e autoritarismo na conformação da ditadura cubana.

Palavras-chave: Revolução Cubana; Heteronormatividade; Autoritarismo.

\section{A Velha Rosa in the garden of the Revolution: cultural tensions, homosexuality, and authoritarianism in Cuba}

\begin{abstract}
This article explores sociocultural dynamics in Cuba in the 1950s-60s through Reinaldo Arenas' short story A Velha Rosa (1966 to investigate the implications of cultural changes, the affirmation of new subjectivities and non-normative sexualities in conformation of the revolutionary process, nationalism, and authoritarian policies of the Cuban regime after the victory of the revolution in 1959. Taking literature as a historical source, the hypothesis is that the context of radical social change stimulated the possibility of abolishing or modifying sexual hierarchies, leading to coercive measures of heteronormative foundation that re-actualized, at a more severe degree, the political and social exclusion of homosexuals on the island. We seek to problematize the hegemonic vision of the revolutionary experience restricted to the anti-imperialist struggle by relating sexuality and authoritarianism in the conformation of the Cuban dictatorship.
\end{abstract}

Keywords: Cuban Revolution; Heteronormativity; Authoritarianism.

Artigo recebido em: 31/08/2021

Artigo aprovado para publicação em: 15/11/2021

\footnotetext{
${ }^{1}$ Mestre em História Social no Programa de Pós-Graduação em História da Universidade Estadual de Montes Claros (PPGH/Unimontes) e professor da Rede Estadual de Educação Básica de Minas Gerais. O artigo é resultado da pesquisa "Reinaldo Arenas: revolução, nação e homossexualidade em Cuba (1959-1980)", financiada pela CAPES. ORCID: 0000-0003-4625-3049. E-mail: jorges.ribas@outlook.com
} 


\section{Introdução}

A organização política da sociedade é inseparável de sua organização sexual. Como demonstrou Michel Foucault (1988), a formação do Estado moderno no ocidente, desde o século XVIII, foi marcada pela introdução do sexo nos cálculos do poder. A estabilidade social (e nacional) foi associada a um padrão sexual considerado ótimo e saudável, regulado pela reprodutividade da população conferida pela disposição fixa dos corpos e dos prazeres no interior da lógica heterossexual. A sexualidade, enquanto "dispositivo" em torno do qual se determinam e conduzem os comportamentos sexuais dos sujeitos, passou a ser central na constituição de representações e imaginários sociais que constituem, por outro lado, hierarquias e modelos de conduta que estabelecem relações de poder desiguais, fundamentadas em normas socialmente estabelecidas que prescrevem a heterossexualidade como expressão correta dos desejos, e a homossexualidade como desvio, anomalia e perversão. Como tal, a conduta sexual de um povo passa a ser uma pedra angular na preservação e na organização política e social como um todo. Contudo, a imposição e a subversão de normas sexuais atravessam o funcionamento social e, na medida em que se manifestam, cabe entendê-las como uma constante nas tensões culturais, na desigualdade social e como forças motrizes para transformações ou desencadeamento de conflitos que tendem a ser geridos pelas instituições, como a nação e o Estado. ${ }^{2}$ Se por um lado a sexualidade constitui a organização social - implícita e explicitamente - por diversos meios e discursos, conformando um ponto-chave na compreensão da vida política, cultural e intelectual, por outro, é também central para compreender as expressões autoritárias do Estado na criminalização e repressão de sujeitos que não se adequam às normas. Em outros termos, pelo gerenciamento da sexualidade, constróem-se ou reforçam-se a legitimidade e atuação de regimes políticos arbitrários. ${ }^{3}$

\footnotetext{
${ }^{2}$ Embora o texto focalize a sexualidade, não se ignora a perspectiva feminista da consubstancialidade das relações sociais, que aponta a interdependência das relações de poder de classe, raça, sexo e gênero na construção social e na identidade nacional (HIRATA, 2014).

${ }^{3}$ Conforme verbete de Mario Stoppino (1998), o "autoritarismo" se define geralmente pela repressão resultante da concentração do poder político nas mãos de um indivíduo, grupo ou de um órgão que reduz ou regula a ação de outras instâncias sociais representativas. Porém, um regime autoritário não necessariamente se constitui pela imposição simples de um indivíduo ou grupo, nem se exerce absolutamente pelo medo imputado à sociedade
} 
A condição instável da heteronormatividade ${ }^{4}$, que se entende como natureza sexual humana sob constante ameaça de degeneração, produz consensos sociais e dissidências em torno de regimes políticos autoritários por meio de controle e supressão das expressões não convencionais que denunciam sua artificialidade. A questão não raramente é tomada como pauta nacional, como problema a ser resolvido pelo bem da civilização, da moral e dos bons costumes.

Somente nas últimas décadas ganham lugar estudos que buscam entender o Estado e a nação a partir de demarcações sexuais. Isso se deve tanto pela prevalência da ótica heteronormativa da história quanto à evidente perseguição aos dissidentes sexuais, que foram excluídos do exercício de cidadania na modernidade, suas vozes silenciadas, os espaços de discussão e contestação minados, controlados e submetidos pela força. Dessa produção organizada de esquecimentos tem-se a impressão de que disputas e resistências nesse campo não existiram ou se deram em casos isolados. Além disso, tais ações de controle e repressão dos corpos não foram vistas como pertinentes para a compreensão dos fenômenos nacionalistas pela historiografia da nação, talvez por serem arbitrariedades amplamente aceitas e partilhadas, ou no mínimo incômodas, que acabam por firmar interpretações da formação nacional em torno de quadros fixos de libertação nacional, luta anti-imperialista e desenvolvimento econômico na América Latina, liderados por grandes heróis que, em si, funcionam como modelos heterossexuais incontestes a serem imitados e reforçados no tempo. Contudo, as disputas e resistências no âmbito sexual estiveram presentes de alguma maneira e se refletem diretamente nos acontecimentos políticos e na construção da identidade nacional

civil, mas sua natureza se nutre também de variados níveis de consensos sociais que legitimam, por diversas razões e em diferentes contextos históricos, o modus operandi autoritário. No caso cubano, o sistema político autoritário é caracterizado pelo unipartidarismo do PCC (Partido Comunista Cubano), pela centralização política em torno do líder Fidel Castro, altamente personalista, pela progressiva neutralização e eliminação das forças consideradas dissidentes ou opositoras, recorrendo a instrumentos de contenção como conformação ideológica, controle dos meios de comunicação, censura, prisões arbitrárias e exílio (HILB, 2010). O autoritarismo do regime se manifesta também nas políticas de perseguição sexual, materializadas no isolamento, censura, prisão e tortura em campos de trabalho forçado para homossexuais e outros dissidentes.

${ }^{4}$ A "heteronormatividade" é um regime discursivo formado por enunciados científicos, jurídicos, religiosos etc., construídos historicamente, que determina como relações sexuais humanas "normais" ou inteligíveis apenas as estabelecidas no interior da "matriz heterossexual". Os sujeitos que não se enquadram nessa norma são marginalizados e destituídos dos direitos de cidadania em determinada configuração social (BUTLER, 2013, p. 215). 
do continente. ${ }^{5} \mathrm{Se}$ os vestígios dessa experiência contestatória não estão nas fontes mais corriqueiras, oficiais, aparecem nas sutilezas literárias, nos escritos privados, na ficção, nas memórias.

No livro sobre $A$ construção social dos regimes autoritários: Brasil e América Latina, as organizadoras Denise Rollemberg e Samantha Viz Quadrat (2010, p. 17) lançam uma proposta

\begin{abstract}
$\mathrm{O}$ que se quer compreender é como, ao longo do século XX, o consenso, frequentemente, se formou em padrões não democráticos, sem que essa ausência tenha sido percebida pela sociedade contemporânea como um problema. Portanto, interessa verificar concretamente como os consensos foram criados; como as acomodações de interesses fizeram-se em regimes autoritários através de mecanismos traduzidos em ganhos materiais e/ou simbólicos para as sociedades.
\end{abstract}

Embora os textos que compõem o volume não abordem o lugar das relações de sexualidade e gênero na conformação do autoritarismo nos países da América Latina, privilegiando outras abordagens, a proposta pode ser ampliada para a relação direta, intrínseca, entre autoritarismo e sexualidade, que afeta intimamente a vida social, produz consensos e funciona como pauta política importante na relação entre Estado e sociedade, mesmo que às vezes de forma inadmitida ou silenciada como zona maldita. Regimes se instituem, estabelecem e legitimam-se em torno de maior ou menor adequação a um sistema sexual específico e em constante mutação.

Aqui pretendo refletir como a perseguição à homossexualidade esteve no cerne da conformação autoritária do regime revolucionário cubano instaurado em 1959. O regime promoveu uma perseguição sistemática às minorias sexuais, tomando a erradicação da homossexualidade como medida necessária para a emancipação nacional e consumação da sociedade socialista, igualitária e justa, não admitindo nisso nenhum paradoxo. $\mathrm{O}$ autoritarismo do regime foi marcado profundamente por preceitos sexuais e morais organizados no discurso revolucionário, que no contexto específico de libertação nacional, associou as dissidências sexuais a uma das pragas da colonização estrangeira. Esse fenômeno problematiza a visão hegemônica na historiografia de que a ditadura cubana se estabeleceu e

\footnotetext{
${ }^{5}$ Sobre o assunto, Cf.: PRATT (1994); PRADO (2004); BEJEL (2006); MADERO (2016; 2005); ROBAINA (2005); CHOMSKY (2015).
} 
se legitimou basicamente como resposta positiva à neocolonização política e econômica dos Estados Unidos às ameaças de intervenção estrangeira e agressões imperialistas. ${ }^{6}$

Contudo, não se trata apenas de reconhecer e apontar a perseguição, ainda que sejam tarefas importantes. É necessário historicizá-la de modo a não reproduzir um discurso que naturalize a opressão. O contexto revolucionário dos anos 1960 em Cuba foi composto por um mosaico de forças plurais que buscaram se estabelecer no entusiasmo da vitória até sucumbirem à ortodoxia ideológica no final da década (MISKULIN, 2009). A efusão intelectual e literária desencadeada pôs em circulação a defesa de múltiplas subjetividades e a expectativa, para muitos, de maior afirmação sexual. A emergência de uma perspectiva diversificada da sexualidade e dos desejos parece ter desencadeado certa ansiedade coletiva e pânicos morais, fazendo com que a homossexualidade fosse considerada pelos dirigentes guerrilheiros um flagelo social. A resposta do regime às modificações nos costumes e à expectativa de liberação sexual em curso, foram justamente a reafirmação heteronormativa, higienização e controle social, isolamento, censura e encarceramento das dissidências em função da manutenção da norma. O que fazer com a vida sexual dos cubanos esteve no centro do furacão político.

A defesa da identidade nacional revolucionária, capitaneada pelo "Líder Máximo" Fidel Castro, envolvia combater inimigos externos e internos considerados contrarrevolucionários. Os homossexuais foram alvos privilegiados na guerra revolucionária, responsabilizados pela fragilidade da nação, sendo que para combatê-los, a sociedade foi mobilizada.

A questão sexual no "espetáculo de ideias" (ROJAS, 2007) que acompanhou a vitória da revolução em 1959 e os anos subsequentes é fundamental para revisar interpretações consolidadas e compreender a complexidade da experiência coletiva e da construção da nova sociedade. Aqui, o assunto será experimentado por meio do conto $A$ velha Rosa, datado de 1966, do escritor Reinaldo Arenas. Relacionando Literatura e História, ao

\footnotetext{
${ }^{6}$ Essa tendência está presente em vários autores brasileiros. Cf.: FERNANDES (2007); AYERBE (2004); BANDEIRA (1998); SADER (1992); CARVALHO (1988). Uma análise geral dessa abordagem pode ser vista em WASSERMAN (2012). Para uma leitura crítica da consolidação do regime após 1959, ver: REIS (2013) e HILB (2010).
} 
apontar a presença da questão homossexual na aurora revolucionária, a intenção é reinterpretar o processo histórico ao abordar as tensões culturais na construção da sociedade revolucionária em torno da (homo)sexualidade. ${ }^{7}$

\section{A Velha Rosa, de Reinaldo Arenas}

O enredo é composto pelos personagens que se destacam separadamente, mas que podem ser entendidos como diferentes cômodos de uma casa. Eles atuam como partes separadas, mas simultâneas, de um mesmo fenômeno: a revolução. A história está ambientada nos anos precedentes e exatamente posteriores a 1959.

O conto começa com a morte de Velha Rosa. Inicia-se pelo desfecho, pelo fim consumado, pela fatalidade. Todos a reconhecem pelos traços de seu semblante, a velhice lhe é constituinte como marca ineludível: é a Velha Rosa. Após a abertura, que já informa a aniquilação da personagem central, dá-se o recuo temporal para narrar a sucessão dos fatos precedentes, intercalando passado e presente, e que levariam ao fogo destrutivo, à casa desabada, à desolação e ao fim de uma vida, existência ou época que se perdeu, que passava.

Logo se percebe que Rosa não é chamada de "Velha" apenas pela idade, pela materialidade do corpo, mas por se tornar antiquada quanto ao ambiente em que vive. A inadequação é metaforizada por sua presença incômoda num ambiente inquieto, resignada, morrendo entre as chamas. Passado e presente estão em choque através de Velha Rosa. Um mundo era perdido, deixado para trás, por assim dizer, mas que era coerente com sua existência, identidade e modo de vida. Um mundo em que estava devidamente situada. "Velha" indica sua condição social mais que biológica. Sua velhice é o lugar de tensão de uma

\footnotetext{
${ }^{7}$ Reinaldo Arenas (1943-1990) nasceu na província de Holguín, Cuba. Autor de vários livros, foi escritor e poeta censurado e perseguido devido à sua homossexualidade e ao teor de seus escritos. Acusado de abuso sexual, crime que não cometera, Arenas foi preso em 1974 e conseguiu escapar, escondendo-se no Parque Lênin durante mais de um mês. Foi capturado e encarcerado por dois anos na prisão de El Morro e depois na Villa Marista. Nesse período, diz em suas memórias ter tentado suicídio duas vezes (ARENAS, 1995). Em 1980, Arenas foge clandestinamente de Cuba no êxodo Mariel, quando aproximadamente 125 mil cubanos deixaram a ilha pelo porto Mariel rumo aos Estados Unidos, depois do incidente em que milhares de pessoas invadiram a embaixada peruana em busca de asilo político e exílio. Após dez anos exilado, Arenas cometeu suicídio em 7 de dezembro de 1990 na cidade de Nova York.
} 
época. É sobre o que e sobre quem passa a locomotiva da história, dos acontecimentos que arrogam antecipar o futuro. Acabou-se o tempo em que "era somente Rosa. Rosa, a filha de Tano; Rosa, a mais nova da família; Rosa, a que conseguia ouvir os rádios de pilha; Rosa, a das pernas perfeitas. Rosa de Pablo" (ARENAS, 1996, p. 10-11). ${ }^{8}$

Do encontro com Pablo, seu futuro esposo, geraram 4 filhos (o último morre prematuramente), e ao longo do crescimento destes a história se materializa e surge a Velha Rosa, devastada pelos acontecimentos fora de controle e que oferece a ótica da narrativa. Os filhos sobreviventes são Pablo Armando, Rosa María e Arturo. No desdobrar dos eventos, Velha Rosa rompe com todos eles.

Impõe-se uma disputa de gerações, de mundos incompatíveis. Uma colisão da qual está surgindo algo como uma sociedade alternativa trazida pelos ventos da revolução.

Velha Rosa tem uma visão extremamente moralista do sexo. Mesmo casada, recusava o sexo com o marido, atordoada por superstições religiosas que tomavam o sexo como impureza. Sua posterior ruptura com a filha, Rosa María, será devido ao comportamento sexual desta, que "loura, quase albina, mas muito saudável” (grifo meu, p. 17), casa-se com um homem negro no povoado, fora da fazenda, e sem consultar a família. Adiante, a tentativa de assassinar seu filho Arturo, sobre o qual nos deteremos posteriormente, será devido à homossexualidade do caçula. Velha Rosa é a compostura, o autocontrole sexual moralista, tradicional, camponês, que parecem se tornar obsoletos ao seu redor. Ela mesma só perdeu a virgindade com o marido depois de dispor todas as imagens de santos e colocá-los num altar do quarto, como vigias das tentações e da perdição.

Primeiramente, vigiou e reprimiu a sexualidade conjugal, sua e do marido. Depois, a dos filhos. Menos de Pablo Armando, o primogênito, cujas noites de alcova no povoado ela aprova publicamente e não o censura: "É para isso que ele é homem”. Quando ele nasceu, disse: "Outro homem para trabalhar" (p. 17). Pablo Armando é o exemplo de masculinidade heteronormativa, "forte e sadio". Não por mera coincidência será guerrilheiro e representante oficial da revolução na trama.

\footnotetext{
${ }^{8}$ É utilizada aqui a edição brasileira de $A$ Velha Rosa: Tradução de Silvia Costa. Rio de Janeiro: Record, 1996. Adiante as citações diretas do enredo pertencem à mesma edição, portanto, será informada apenas a paginação.
} 
Velha Rosa é mantenedora da ordem cultural pré-revolucionária e viciada em ordenar. Ela necessita de que nada esteja fora do controle. As várias imagens de santos, aos quais recorre sucessivas vezes, impõem-se como sistema simbólico de uma visão de mundo, sua organização, condutas e valores.

"Uma noite descobriu [...] que já não era jovem e que os vizinhos não a chamavam de Rosa, mas de Velha Rosa” (p. 23). Esse átimo, como divisor de águas, é emblemático, e marca a reviravolta na história, em que o reinado de Velha Rosa, com sua ordem matriarcal ortodoxa, de calmaria e precisão, é desestabilizado. Os filhos cresceram com horizontes próprios, mudanças comportamentais, atritos geracionais e visões de mundo outras. Corriam os anos 1950, chegou a revolução e com ela o furacão político, social e econômico. Rosa torna-se Velha Rosa ao ficar deslocada diante dos acontecimentos. Seu lugar no mundo e sua forma de entendê-lo são ameaçados por ventos incompreensíveis, imprevisíveis. O fato de Velha Rosa, que queria controlar até o tempo, não assimilar as mudanças ao seu redor, fazem-na velha, relíquia de um mundo caduco. O envelhecer de Rosa é paralelo à inovação e à mudança social encarnadas em seus filhos.

Mas a dicotomia entre passado versus presente é só aparente. Não se trata de uma história teleológica ou ingênua de superação do passado e progresso do futuro, mas de interação conflituosa de forças sociais num contexto de profundas mudanças nas relações de poder. O que interessa é que forças são essas, a partir de cuja tensão o passado encontra formas de permanecer, em vez de acabar.

O ciclo contínuo da vida é interrompido quando a revolução acontece, e Pablo Armando adere à luta guerrilheira e retorna vitorioso, contra as expectativas da mãe: "Na verdade, desde aquele dia as coisas não voltaram a ter, para a Velha Rosa, o equilíbrio invisível que até então haviam conservado. [...] algo tinha mudado" (grifo meu, p. 31).

Pablo Armando se tornou um oficial revolucionário e mediou a intervenção estatal nas terras de sua mãe, sem a anuência desta, retirando dela a autoridade e o domínio de sua propriedade, que tivera por trinta anos. Rosa María, que saíra de casa para estudar no povoado, era estranha aos hábitos da mãe, à sua propriedade, emancipou-se, letrou-se, casou-se sem a bênção da família com um homem negro e lhe negou satisfações. Velha Rosa, 
ao saber que seu genro era negro, quis se matar. "'Que desgraça tão grande', disse Velha Rosa. 'Ah, mamãe', disse Armando, 'deixe de bobagens que as coisas não são mais assim; agora todo mundo é igual"” (grifo meu, p. 37). "Agora", advérbio de tempo, traduz o momento da revolução como ruptura em relação ao passado e à aceleração na mudança dos costumes. E é, também, um horizonte desejado coletivamente. A defesa de Pablo Armando à independência da irmã e a cumplicidade de Arturo demonstram um posicionamento partilhado pelos três filhos. Afinal, os dois irmãos foram coniventes com Rosa María em detrimento da postura racista de Velha Rosa: "No dia que eu for igual a um negro, me enforco"; "Já não é mais minha filha"; "Um negro, dizia agora em voz alta, um negro. Mas é incrível. Que tempos estamos vivendo. Onde iremos parar" (p. 37).

A contraposição dos filhos à mãe, que simboliza o passado obsoleto, uma âncora do atraso, amplia a visão simplista sobre o processo revolucionário cubano, na qual a mobilização social se reduz à luta de um povo contra a opressão imperialista. Há muito mais em jogo, o quadro é mais complexo. A euforia revolucionária faz emergir com mais vigor expectativas culturais, desejos, subjetividades e mudanças comportamentais de forças históricas que se modificavam. A revolução também significou possibilidade de mudanças nas relações de poder cotidianas, na organização social, familiar, geracional e sexual que se transfiguravam na década de 1960. Essa perspectiva extrapola as razões políticas nacionais dos dirigentes, que embora sem dúvida sejam determinantes no desencadeamento da guerra e na derrocada do ditador Fulgêncio Batista, não explicam totalmente a miríade de interesses que arrastou as multidões que declaravam que o mundo (leia-se Cuba) não seria mais o mesmo.

Tudo o que aflige e abala as certezas de Velha Rosa é associado à revolução: o primogênito rebelde, o guerrilheiro Armando, que seria herdeiro direto da fazenda, mas torna-se revolucionário, volta-se contra a autoridade da mãe (família) e adere à autoridade do Estado, que se consuma ao entregar as terras para a cooperativa durante a reforma agrária, contra a vontade de Velha Rosa. Também a apavora a ideia de igualdade racial, representada na filha emancipada e autônoma sexualmente, avessa às tradições de devoção e submissão femininas. 
À essa altura, a última peça que lhe falta para cerrar seu túmulo é o caçula, em quem ainda confia e desabafa: "Estou morta, disse a mãe [...]. Ai, Arturo, é o fim do mundo" (p. 47). Mas Velha Rosa é a expressão histórica de um mundo que, se parece acabar, recusa-se a desaparecer. Se sua autoridade não se sobressaiu em relação a Armando e Rosa María, não se pode dizer o mesmo sobre o desfecho de sua relação com Arturo. 


\section{Arturo, o filho homossexual}

"E quatro anos depois chegou Arturo, prematuro e chorão, que sofria de constantes febres; foi um milagre que se salvasse” (p. 17). A comparação entre Arturo e Pablo Armando é inevitável. Arturo é frágil, superprotegido, que vive em seu quarto, isolado, estranho, ouvindo músicas que Velha Rosa não compreende. Não se interessa pela fazenda, pelo trabalho, não se interessará pela revolução. É o filho homossexual que terminará a história fugindo da mãe, que tentou matá-lo com tiros de espingarda ao ser flagrado tirando a roupa e beijando outro rapaz no quarto.

Seu papel na trama é um tanto impreciso, pois parece não ter outra finalidade que a de ser o filho caçula. Ele parece desambientado em relação aos acontecimentos da fazenda e ainda em relação à própria mãe: "De seus três filhos, era de Arturo que ela mais gostava [...] $\mathrm{Na}$ verdade, algumas vezes a Velha Rosa olhava-o com desconfiança, tinha a impressão de que seu filho era um desconhecido" (grifo meu, p. 24). Uma passagem, contudo, demarca a tensão que não abandonará mais os dois personagens, e outra vez, mãe e filho, como duas situações diferentes no mundo, estão em atrito. "E assim, quando Arturo cismou de comprar um rádio de pilhas que custava um dinheirão e mandou construir uma torre junto à casa, onde se instalou com o rádio e começou a reunir os meninos das vizinhanças, o rosto da Velha Rosa ficou um pouco mais sombrio" (grifo meu, p. 24-25).

$\mathrm{O}$ rádio, os atos suspeitos, a total indiferença à vida na fazenda e a vontade de ir embora para o povoado separam Arturo de Velha Rosa. Seu personagem também demarca a presença homoerótica em meio aos acontecimentos revolucionários, no interior do microcosmo da fazenda, e revela a tensão. No conjunto, essas características tornam-no mais complexo que os outros filhos. O rádio, enquanto artefato tecnológico de dispersão cultural, é inseparável de seu dono, e parece demarcar a postura "jovem" de Arturo, sua conduta ensimesmada, com códigos próprios que o conectam a outros jovens das redondezas num universo próprio, que Velha Rosa não reconhece: "Do quarto de Arturo, o rádio deixou escapar o estrondo de uma música da moda. E embora aquela música lhe fosse intolerável, a Velha Rosa não disse nada" (grifo meu, p. 50). Isso sugere a presença de uma juventude 
interligada por valores culturais e referências que acabam por separar os filhos dos pais, demarca uma mudança geracional que, inclusive, foi marcante nos movimentos de contracultura dos anos de 1950 e 1960. Arturo (e seus irmãos, de diferentes formas) são agentes desse fenômeno. E vale lembrar que uma das marcas da revolução cubana, que contribuiu para definir o espírito libertário da época, foi a face jovem de seus líderes, o que impulsionou sua associação à contestação juvenil, que levou o rosto de Che Guevara a ser o mais divulgado do mundo, principalmente nos acontecimentos de maio de 1968 (HOBSBAWM, 1995; CASTAÑEDA, 1996). Além disso, não se deve esquecer de que a década de 1960 é também a da eclosão dos movimentos pela liberdade e direitos civis dos dissidentes sexuais, o que possui fortes ressonâncias na escrita de Reinaldo Arenas.

Mas Velha Rosa, representante do passado a ser superado, tal como as forças pretéritas, não se deixa vencer facilmente. Sua tendência é perpetuar-se.

A revelação da homossexualidade de Arturo coincide com o fim da história e com a tentativa de assassinato do filho pela mãe, sem discussões. Para Arturo não há resignação, como em relação a Armando, senhor de tudo; nem a morte simbólica é suficiente, tal qual a de Rosa María deserdada; mas a morte mesma, física, é a solução vislumbrada por Velha Rosa para o filho gay, para não lhe permitir futuro.

No problema homossexual de Arturo, tradição e inovação colidem. E o passado se reatualiza.

O rompimento de Velha Rosa com Arturo é carregado de significação histórica quanto ao lugar da homossexualidade no interior da tensão social precipitada pela revolução. Arturo é a afirmação e a vivência do desejo homoerótico, e como filho da Velha Rosa, é também habitante da sociedade revolucionária, portanto, funciona como esperança e projeção para o porvir. $\mathrm{O}$ desfecho entre os dois guarda um enigma que fundamenta a historicidade do conto. O ponto reside na arma que Velha Rosa utiliza para tentar assassiná-lo. Tempos antes, quando Armando voltou anunciando a vitória da revolução (e despertou os maus pressentimentos da mãe), ele pendurou na parede da casa, feito num altar, a espingarda que utilizara na guerrilha, atualizando a simbologia sagrada, destacando o signo revolucionário, para receio de Velha Rosa adoradora de santos. E a arma que Velha Rosa utiliza para atirar 
três vezes em Arturo é justamente a espingarda da guerrilha. A arma revolucionária é-lhe a única coisa útil proveniente da revolução, porque serviu para aniquilar o filho homossexual. É por meio dessa arma e desse ato que Arenas aponta a revivificação do passado no presente da revolução, aquilo que não é superado, mas readmitido sob novas formas. Velha Rosa armada com a espingarda que simboliza a guerrilha expressa a simbiose entre a revolução e a tradição homofóbica, aquilo que não é ultrapassado, que não seria visto como antiquado ou obsoleto, pelo contrário, que se complementaria e se reforçaria. É a fronteira na qual a igualdade expressada por Armando ("Agora todo mundo é igual”) não alcança. Arturo foge sem rumo, pouco antes da destruição completa da fazenda e de Velha Rosa, corre a vagar com destino incerto no horizonte.

Nos primeiros anos da revolução, as perseguições à homossexualidade se aprofundaram.

Arturo será novamente personagem em conto posterior de Arenas, Arturo, la estrella más brillante (1971), que funciona como a continuação de A Velha Rosa. Arturo reaparece como prisioneiro num campo de trabalho forçado por ser homossexual, assombrado por fantasmas do passado, pelo guerrilheiro Armando e pelo espectro de Velha Rosa, armada e vestida de militar.

As revoluções, com sua carga de transformação e novidade, trazem consigo, inevitavelmente, ressonâncias e repetições. E também retrocessos.

A Velha Rosa estava longe de ser uma adepta da revolução, tampouco queria conviver com a homossexualidade. A revolução também não conviveria.

\section{Literatura, História e Revolução em $A$ Velha Rosa}

Toda literatura é feita em circunstâncias de ordem histórica.

A escrita ficcional de Reinaldo Arenas na primeira década da revolução revela um observador acurado das mudanças de seu tempo. Arenas organiza no discurso literário a experiência histórica das expectativas do presente revolucionário, que se mostra como um atrito entre o passado e os futuros possíveis. Diferentes sujeitos, de acordo com seu lugar 
social, criam diferentes expectativas. Ao contrário do discurso oficial que reduz a experiência coletiva da revolução à ótica guerrilheira, e que impôs a visão escatológica da história, etapista, concebendo o futuro como algo previsto e controlável pela ortodoxia ideológica, para Arenas o presente revolucionário é o lugar escuro das possibilidades, num momento de mudanças radicais e esperanças, mas que se resolvem no interior da organização social ancorada num passado mais complexo, herdeira de estruturas patriarcais e raciais, além de econômicas, que são elementos centrais da identidade coletiva, dos traços subjetivos e das condutas sociais em disputa.

O racismo e a homofobia, encarnados em Velha Rosa, eram fraturas sociais que impediam uma sociedade harmônica e, como tal, seria inevitável que fossem enfrentadas pelos indivíduos e pelo novo regime político.

E o foram. As mudanças sociais que significaram o "fim do mundo" para Velha Rosa, e que resultou na sua morte social, impõe na narrativa a defesa e expectativa de um futuro de convivência racial e sexual.

História, literatura e sociedade estão bem relacionadas. A literatura é um testemunho, pertence à determinada sociedade e informa sobre a experiência humana não por narrar os fatos, mas o simbolicamente verdadeiro. Isso quer dizer que a literatura é uma fonte privilegiada de acesso aos anseios, medos, expectativas, desejos, temores coletivos e tensões que ocorrem no interior de uma estrutura social em determinada época. Ela configura um posicionamento diante do real, uma forma de qualificar o mundo que dá acesso ao imaginário, aos fenômenos velados e subjacentes aos processos históricos, "fornecendo pistas e traços daquilo que poderia ter sido ou acontecido no passado" (PESAVENTO, 2006, p. 22). Ou ainda, a ficção é um recurso codificado para expressar e defender aquilo que é difícil dizer explicitamente, devido às interdições sociais e aos traumas da experiência (SAER, 2012).

Para assumir a dimensão histórica e social da literatura de Arenas, é necessário clareza dos marcos fundadores de sua criação literária. O ano de 1959, do advento revolucionário, é um divisor de águas nas artes cubanas em geral, especialmente nas letras. Isso impõe uma marcação temporal que desencadeia um estado social marcado pela crise, que se reflete na intensidade intelectual e cultural do período. Diante disso, a literatura se firmará 
como veículo catalizador de processos históricos, de revisão do passado e projeção do futuro, entendida como vetor eficaz de transformação social possibilitada pela efusão revolucionária (ROJAS, 2007). O contexto em que Arenas escreve é marcado pela remodelação do papel do intelectual na sociedade, cuja ação deve promover a transformação social e a conscientização coletiva. É imperativo falar da revolução e utilizar dos recursos ficcionais para consolidar a nova ordem e superar a antiga. A literatura toma uma dimensão pedagógica, ainda que se mantenha complexa no caso de Arenas, mas sempre atenta à uma missão política pertinente ao momento (CANDIANO, 2021). Essa condição difere a produção literária pós-1959 da produzida anteriormente e permite delinear, no plano histórico, um ângulo estratégico de avaliação das diferentes alternativas que se puseram no presente para realizar o futuro; das tensões dos novos ajustes sociais, dos projetos coletivos, possibilidades e desafios que poderiam ou pareciam ser praticáveis e que entraram em disputa. Não significa que as demandas irrompidas tenham surgido somente em 1959, mas que pareciam agora poder alterar, ainda que simbolicamente, a ordem das coisas. Por isso deve-se observar as mudanças profundas dos quadros mentais expressas em metáforas e personagens que traduzem aspirações e remodelações das práticas sociais existentes.

Assim, as tensões manifestadas no interior da ficção informam sobre as rupturas e permanências históricas, perturba, clama e interroga por meio de representações de sujeitos inconformados e desajustados socialmente. Pelo crivo das relações de gênero, sexualidade e raça, critérios organizativos da sociedade que fundamentam processos de subalternização e invisibilização, novos sujeitos tomam o palco da história a partir dos vestígios literários que abrem fissuras no silêncio e buscam redenção para indivíduos aflitos, revelando o espírito inquieto de uma época. ${ }^{9}$

\footnotetext{
${ }^{9}$ Literatura como Missão: Tensões Sociais e Criação Cultural na Primeira República, de Nicolau Sevcenko (2003), e $O$ desejo da nação: masculinidade e branquitude no Brasil de fins do século XIX, de Richard Miskolci (2013), são duas referências que comprovam a viabilidade do uso da ficção literária para investigação histórica. Os autores tomam produções literárias situadas na transição da Monarquia para República no Brasil para abordar os conflitos (de classe, raça, sexualidade e de gênero) que atravessam a construção de uma nova identidade coletiva e nacional. Um novo projeto político modernizante impõe novos imaginários simbólicos, atuantes na redistribuição dos papéis dos atores sociais, admitindo uns e excluindo outros de acordo as condições estratégicas de poder do período.
} 
Como foi mencionado, a passagem da década de 1950 para a de 1960 guarda uma profunda carga de transformações sociais e culturais, principalmente nos espaços urbanos, marcadas pela "modernização" dos costumes, que se traduziu na modificação das relações sexuais, raciais e entre gerações; no avanço tecnológico e na afirmação progressiva de uma cultura juvenil que se demarcava como categoria social independente (HOBSBAWM, 1995). Em Cuba, seus efeitos foram sentidos acentuadamente nas circunscrições da capital $L a$ Habana, núcleo populacional cosmopolita da vida política e cultural do país. Se essas mudanças sensíveis não foram sentidas como grande acontecimento político pelo menos até 1968, foram amplamente significativas na medida em que afetavam a vida cotidiana e modificavam a paisagem humana. A revolução se dá num ambiente cambiante das relações sociais, que é inseparável do processo revolucionário, e irá interferir na configuração do nacionalismo pós-1959, que se estabelece em íntima interação e reação a esse fenômeno cultural. O tradicional enfoque nacional anti-imperialista do processo revolucionário negligencia essa relação, na qual o próprio nacionalismo se constitui e está imerso, e sem a qual não se compreende satisfatoriamente a natureza histórica da revolução cubana.

As mudanças em torno dos costumes, sexualidade, raça e cultura juvenil tomaram lugar central no debate político pós-revolução, gerando desde medidas igualitárias a imposições, repressão e traumas coletivos no cerne da formação de uma nova cultura nacional.

Tudo isso é apagado quando se representa a história a partir de indivíduos heroicos de forma obsessiva. A consequência é a construção de uma memória histórica que coopta os movimentos plurais para encaixá-los no quadro estreito do anti-imperialismo, que, se de fato foi decisivo, não foi tudo.

Outra consequência ainda mais grave é que o anti-imperialismo oficial se torna um dispositivo para justificar o autoritarismo, o controle e a opressão de sujeitos que, no fundo, foram motivadas por razões outras, de desígnios sexuais e raciais, agora obscurecidas no labirinto do esquecimento.

É necessário definir um ângulo de observação que interprete o entusiasmo com a vitória revolucionária em 1959, expresso em manifestações artísticas mais diversas, 
especialmente na literatura, como algo motivado também pela presença de uma disposição libertária mais completa, para redefinir as relações sexuais e raciais na sociedade, bem como contestar hierarquias e valores tradicionais, articulando-as como pautas importantes na reconfiguração da cultura nacional. Tais projeções não surgiram da noite para o dia, e sim que tiveram condições de emergir, delinear e amadurecer no ambiente de maior liberação/libertação dos anos 1950-60.

Não se trata, evidentemente, de negar o peso da colonização, as lutas pela independência e a questão nacional em Cuba, mas de atentar para a instrumentalização dessas categorias e para o fato de que possuem um caráter homogeneizante e reducionista da história. O regime instaurado em 1959 e seus objetivos políticos passaram a encarnar o ideal de nação e sua exata medida; rapidamente Fidel Castro tornou-se seu porta-voz inconteste, regulando no interior de condições dadas seus sentidos e significados, que resulta numa perspectiva histórica que possui numerosas zonas de silêncio.

Uma das zonas marginalizadas na historiografia da revolução é o tema da homossexualidade e do homoerotismo ${ }^{10}$ (MADERO, 2006). A denúncia, censura, prisão e o envio de homossexuais para campos de trabalho forçado nos anos sessenta foram considerados atos patrióticos e de defesa nacional (MADERO, 2016). Em relação a essa perseguição tem-se uma forte contradição: ela foi justificada como ato nacionalista e revolucionário ${ }^{11}$, no entanto, a historiografia que valoriza a questão nacional para explicar a revolução silencia sobre o papel importante da perseguição sexual na conformação do nacionalismo e na própria legitimação do regime. A dinâmica autoritária e excludente do nacionalismo, que se coloca acima de todas as diferenças e desigualdades, é muitas vezes ofuscada pela limitação estritamente (geo) política do fenômeno, quando na verdade muito de sua efetivação interna e força mobilizadora se deu pelo reforço de parâmetros morais e sexuais, em torno de padrões heteronormativos arraigados culturalmente e que se viam em crise no período.

\footnotetext{
${ }^{10}$ O termo "homoerotismo" demarca uma postura crítica, inspirada em Jurandir F. Costa (1992), para designar as diversas possiblidades de atração e manifestação erótica entre sujeitos do mesmo sexo, que não definem um tipo sexual uniforme ou uma categoria de sujeito.

${ }^{11}$ Fidel Castro mais de uma vez condenou publicamente a homossexualidade nesse sentido, como mostram seus discursos em 1963 e 1965. Cf.: YOUNG (1984, p. 20); CASTRO (1963).
} 
Não é suficiente, contudo, constatar que houve perseguição às minorias sexuais, muito menos satisfazem versões que a explicam a partir de um determinismo cultural, qual seja, o de que os cubanos em geral eram culturalmente homofóbicos. ${ }^{12}$ Além do mais, a responsabilidade do regime é reduzida porque a homofobia não seria algo exclusivo de Cuba. Essa leitura histórica encerra três problemas: o primeiro é que a ideia de que a homofobia seja uma prática política e social hegemonicamente praticada retira qualquer responsabilidade dos dirigentes políticos e denunciantes das medidas persecutórias, colocando-os como mero reflexo de sua época, sujeitos sem juízo, sendo assim, não existe responsabilidade histórica ${ }^{13}$. O segundo problema é que essa visão borra o passado, fazendo crer que não houve posturas diferentes, proposições, resistências e ações contrárias à perseguição. É como se a sociedade inteira, inclusive as vítimas, simplesmente tivesse aceitado as imposições e o destino de destruição. O terceiro problema, resultante dos dois anteriores, é a imposição de um determinismo histórico, do ponto de vista oficial, no qual nada do que ocorreu poderia ter sido diferente e nenhuma alternativa ao que efetivamente aconteceu é considerada.

Se tudo se justifica pelo contexto, como se este fosse uma zona estanque e homogênea da ação humana, dispensando a compreensão de como tais coisas se tornaram possíveis e porque não foram de outra maneira, o ofício de historiador pode ser considerado inútil. E nada se aprende com as experiências desse passado senão a fatalidade da intolerância.

Tal visão reprodutora de silêncios, para se estabelecer, se dá ao preço da censura, das prisões, do apagamento da memória e consolidação do esquecimento que naturaliza a

\footnotetext{
${ }^{12}$ Esta é a visão oficial do regime, Cf.: LAMRANI (2013), e alguns trabalhos que abordam o tema não vão muito além disso, Cf.: MISKULIN (2009, p. 102-103; 2003).

${ }^{13}$ Fidel Castro assumiu a culpa da perseguição aos homossexuais em 2010, quando afirmou que as urgências nacionalistas do momento, tais como a sobrevivência da revolução, a Crise de Outubro e às ameaças à sua vida, fizeram com que ele não desse atenção às perseguições que ocorriam aos homossexuais. Seus próprios discursos da década de 1960 dão impressão diferente, pois condicionava a defesa nacional e revolucionária também ao combate à homossexualidade, como ações interdependentes. Se antes foram perseguidos porque tornavam a nação frágil e penetrável durante a guerra, com a admissão de culpa por Fidel, a causa foi do pragmatismo ao descuido, mas mantendo a mesma justificativa: a nação precisava ser salva e foi esse o preço. SAADE, Carmen Lira. Soy el responsable de la persecución a los homosexuales que hubo en Cuba: Fidel Castro. La Jornada, 31/08/2010. Disponível em: https://www.jornada.com.mx/2010/08/31/mundo/026e1mun. Acesso em: 29 jul. 2021.
} 
heterossexualidade compulsória, ao eleger os aspectos que configuram a história de um período e excluir outros.

Reinaldo Arenas pluraliza vozes da história de Cuba e coloca no centro da questão revolucionária o destino dos homossexuais em $A$ Velha Rosa ${ }^{14}$ Sua escrita atravessa os acontecimentos políticos, intricados de diferentes posturas e visões de mundo em disputa, que faz emergir, se observada, uma experiência coletiva mais completa, feita de nuances, embates, emoções divergentes, políticas de ansiedade ${ }^{15}$ e pânicos morais. ${ }^{16}$ Esse mosaico compõe a sociedade desigual instabilizada durante a revolução, aflorada num tempo de rupturas cotidianas paralelas à missão de construir uma nova nação e um "homem novo" ideal" curiosamente carregados de passado.

Além de trazer para o plano histórico experimentações anônimas do contexto, a censura e perseguição que Arenas sofreu por ser homossexual tornam premente explicar historicamente a construção de um ideal revolucionário oficial que se faz também mediante marcação e reafirmação de modelos de dominação masculina heterossexual, num cenário de maior despontamento de sexualidades e desejos não normativos dentro e fora de Cuba, que têm efeitos concretos no fenômeno autoritário e nas políticas homofóbicas pós-1959.

\footnotetext{
${ }^{14}$ Outros escritos do autor também mobilizam significados em torno de projeções homoeróticas em Cuba. Em El mundo alucinante (1966), censurada em 1968 e publicada clandestinamente na França em 1969, narra a trajetória de um líder nacionalista mexicano do século XIX, Frei Servando, que representa a identidade nacional incorporando na nação a diversidade sexual, em vez de eliminá-la. Nessa novela nacionalista, a tradição representativa da nação heteronormativa é rompida.

${ }^{15}$ Ariel Rodríguez Kuri (2010), ao analisar as convulsões sociais de 1968 no México, revela a existência de um temor coletivo pelas consequências que certas mudanças poderiam acarretar. Esse temor reflete muitas vezes o receio do colapso de padrões morais num cenário de radicalidade política e social. Daí a "política de ansiedade" poder ser entendida como os componentes emocionais da vida coletiva: o medo, a sensação de incerteza, a imprevisibilidade do futuro que mudanças precipitadas inspiram (KURI, 2010). Esses pânicos, vale dizer, são ativados também pelas hierarquias morais, sexuais e raciais em que se assenta a organização social e que alimenta seus temores de que sejam dissolvidas. Períodos de fortes mudanças aumentam os receios de suas consequências.

${ }^{16}$ Como afirma Richard Miskolci, "pânicos morais" são reações coletivas a supostas ameaças a uma imagem idealizada que uma sociedade tem de si mesma. Eles costumam ser disparados pela ação de empreendedores morais, pessoas, grupos ou meios de comunicação que conseguem a adesão coletiva contra inimigos comuns" (MISKOLCI, 2013, s/p).

${ }^{17}$ A construção do "homem novo" como sujeito ideal revolucionário funcionou como um firme modelo de homem heterossexual que encarnava todas as missões virtuosas, o sacrifício e a honra masculina, diante do qual o homossexual era considerado uma "degeneração burguesa" e uma afronta (MADERO, 2016). O guerrilheiro barbudo, fardado e armado foi sua materialização mais próxima, ainda que incompleta. Sobre isso, ver SADDI (2009).
} 
É insuficiente crer que os valores tradicionais dos cubanos, por si só, ensejariam as $\mathrm{CDR}^{18}$, as $\mathrm{UMAP}^{19}$ e o "homem novo", enquanto instituições físicas e simbólicas de imposição heteronormativa. Em vez disso, o aparato repressivo do regime reage aos impulsos libertários que o clima revolucionário contribuiu para intensificar, aumentar a circulação e afirmação. O nível de perseguição sistemática, organizada e institucional alcançado seria improvável em momento anterior.

Pode-se afirmar, com razão, que nenhuma revolução, ainda que pregue o fim das desigualdades, varre magicamente estruturas sociais duráveis por séculos e "inerentes" à sociedade. Mas uma vez que determinadas estruturas foram postas em xeque, seu agenciamento se deu no âmbito da nação, que buscará estabilizar conflitos de gênero, sexuais e raciais num quadro que contivesse as incertezas de uma mutação imprevisível que tornasse a sociedade, para certos grupos, irreconhecível. A perseguição que se instalou não encontra precedentes em Cuba (MADERO, 2016, 2006; YOUNG, 1984) e os efeitos são sentidos nos dias que correm. ${ }^{20}$

As políticas culturais promovidas pelo regime, de restrição ideológica e sexual, podem ser interpretadas como projeto de redefinição de critérios sociais e morais em mutação, numa sociedade decidida a romper com o passado e a projetar o futuro. Mas esse fenômeno é mais disperso e profundo que os enunciados e silêncios oficiais. Em conjunto, as ações do regime contrapostas a uma literatura subversiva e circulante, traduzem a experimentação simbólica e histórica dessas questões muitas vezes sem materialidade documental nos arquivos oficiais, mas cuja existência e força podemos reconhecer. Certos enredos, com em $A$

\footnotetext{
${ }^{18}$ Comitês de Defesa da Revolução. O combate à contrarrevolução gerou em 1960 essa sofísticada rede de vigilância política e social, que existe até hoje, mas cuja finalidade, além de alfabetização, vacinação e prevenção de doenças, era denunciar dissidências morais e perseguir homossexuais reais ou presumidos (BARRETO, 1994, p. 144-145).

${ }^{19}$ Unidades Militares de Ajuda à Produção. Foram campos militares de trabalho forçado para "reeducação" e "correção" de "desvios" sociais, sexuais e ideológicos, para onde foram enviados, entre outros desafetos políticos, centenas de homossexuais. Não se tem uma data precisa de abertura e fechamento desses campos, mas há um consenso de que tenham sido entre 1965 e 1968. Cf.: MADERO (2016).

${ }^{20}$ A introdução do casamento homoafetivo no Código da Família foi rejeitada na nova Constituição cubana, aprovada em dezembro de 2018, devido a maioria dos cubanos ter sido contra a medida. Ainda que haja iniciativas oficiais a favor da legalização do matrimônio e da diversidade sexual, representada (e regulada) na figura de Mariela Castro, filha de Raúl Castro, o regime teve papel central na institucionalização da homofobia e sua manutenção na mentalidade dos cubanos, a partir de sua incorporação ao discurso revolucionário no passado e de políticas consistentes, conscientes e unificadas do governo.
} 
Velha Rosa, revelam as hesitações que causam mudanças radicais, o pânico que geram quando há o risco de abalo de estruturas tradicionais, de abolir fronteiras que por muito tempo conformaram uma identidade coletiva.

Assim, o período de consolidação revolucionária possui avanços e retrocessos, projeções de futuro múltiplas que foram suprimidas dentro de uma reatualização de hierarquias sexuais. Houve mutações e a reinserção do passado no presente, próprias da dinâmica social, demonstrando que subjacente à demanda nacionalista em 1959, existe a reorganização vigilante das tradições culturais e sociais num período de aceleradas mudanças comportamentais, sexuais e morais, acionada por certo temor de que a sexualidade e a raça ${ }^{21}$ não seriam mais contidas dentro das identidades e hierarquias pré-revolucionárias.

Velha Rosa simboliza o quanto a revolução conservou do passado que procurava superar. E Arturo denuncia-o como testemunho de uma experiência histórica traumática que acompanha toda a literatura de Reinaldo Arenas, na qual os dissidentes sexuais foram os primeiros alvos do autoritarismo. O nacionalismo revolucionário, por operar num país colonizado, não tem "origens puras" no passado para serem resgatadas, o tempo perdido anterior à decadência, como no nacionalismo moderno europeu (HOBSBAWM, 2002). O nacionalismo revolucionário do século XX de países colonizados, se busca o passado, é para combatê-lo. Mas deve-se perguntar o que se combate e o que se busca superar e por que a sexualidade se tornou um campo de batalha. Todos os habitantes nascidos antes de $1959 \mathrm{em}$ Cuba, preconizava Che Guevara, eram portadores do "pecado original" da sociedade colonial, burguesa e capitalista (GUEVARA, 1980). Dos "vícios" burgueses e "taras do passado" a serem erradicados, os homossexuais se tornaram párias como jamais antes, responsabilizando-os pela degeneração social da colonização, como ingerência nociva para enfraquecer o país e favorecer a dominação estrangeira, por meio da corrupção moral dos homens que impossibilitaria a sobrevivência da revolução e do socialismo. Tal associação só

\footnotetext{
${ }^{21}$ As iniciativas autônomas da luta antirracista foram consideradas um fator de divisão da união nacional necessária para a revolução. A partir de 1959, foi decretado que não existia mais racismo em Cuba, tornando-se assunto exclusivo do Partido Comunista. Vários ativistas e intelectuais negros foram censurados, isolados e presos quando pautaram a permanência das heranças escravocratas, a luta racial e a necessidade de manutenção do movimento negro no interior da revolução. $O$ boicote ao movimento e sua cooptação oficial são sintomáticos das formas de manutenção da desigualdade racial na ilha, que existe até hoje. Cf. CHOMSKY, 2015, p. 170-178; MISKULIN, 2009, p. 185-186.
} 
parece explicável diante da paranoia contínua, mas aprofundada, de que a identidade coletiva de marco heterossexual estava ameaçada e que seria salva pela revolução socialista.

Até o final dos anos 1970, essa postura havia sido reforçada. Os primeiros sinais de contenção violenta da sociabilidade homoerótica foram as rondas noturnas da aurora revolucionária, como a mais famosa Noche de las três $P$, de 1961, em que batidas policiais saíram pelas ruas de Havana prendendo prostitutas, pederastas e proxenetas, entre eles o importante dramaturgo cubano Virgílio Piñera, que foi preso e obrigado a vestir um uniforme carcerário grafado com um "P” maiúsculo de pederasta nas costas (BARRETO, 1994, p. 150).

Dez anos depois, quando já haviam sido experimentadas a prisão de homossexuais também nos campos das UMAP e a censura como vigilância permanente, o Primeiro Congresso Nacional de Educação e Cultura, de 1971, definiu o "desvio homossexual" como "patologia social", cujos focos precisavam ser sanados e mantidos sob controle. Para tal, a principal medida era impedir qualquer manifestação pública da homossexualidade, sua existência artística e "influência sobre a juventude", além de solicitar "penas severas para casos de corruptores de menores, depravados reincidentes e elementos antissociais incorrigíveis" (Resoluções, p. 27-29). A perseguição sistemática aos homossexuais como inimigos internos gerou impactos irreversíveis na vida cultural do país. A parametración, como ficou conhecido o processo de enquadramento ideológico, também foi sobretudo sexual e retirou da cena cultural manifestações intelectuais cujo teor não fosse uma reafirmação dos valores sexuais normativos atrelados às conquistas da revolução. No decorrer da década de 1970, a Lei 1249 de 1973, reformulada em 1979, situava a homossexualidade no código penal condenando à prisão todo aquele que "ostentasse publicamente" sua homossexualidade, ou que tentasse, por qualquer meio, "perverter ou degradar os costumes" com sua conduta aberrante e imoral (BARRETO, 1996, p. 164-167). A década de 1980 começou com o forte abalo da crise de Mariel, ocasião em que muitos homossexuais saíram ou foram expulsos da ilha como gusanos (vermes), numa política abertamente sanitarista. ${ }^{22}$ As

\footnotetext{
${ }^{22}$ Arenas, um "marielita", narra em suas memórias que, por estar impedido de sair do país, adulterou seus documentos para Reinaldo Arinas. Sob identidade anônima, para justificar que "merecia" partir de Cuba sem nada que indicasse culpa contrarrevolucionária, encenou um andado rebolado para um tenente e uma psicóloga e afirmou ser sexualmente passivo, "comprovando" assim sua homossexualidade e facilitando sua fuga (ARENAS, 1995, p. 310).
} 
coisas começariam a mudar no decorrer dessa década, com a reabilitação de algumas personas non gratas homossexuais e a admissão paulatina do assunto nos meios culturais. Por fim, a descriminalização da homossexualidade veio no final dos anos 1990 e desde 2007 é celebrado o dia contra a homofobia no país. Os ecos desse passado de perseguição, contudo, são uma ferida aberta na história cubana, e estão inseridos numa disputa de memória e esquecimento entre a narrativa oficial do regime e os testemunhos diversos de dissidentes políticos e vítimas sobreviventes. Novamente a sexualidade se inscreve como eixo em torno do qual o poder político atua, uma vez que a diversidade é regulada pela oficialidade para não resultar, também, em dissidências políticas, e o regime procura legitimar-se por cima dos escombros (NEGRÓN-MUNTANER, 2008).

Não resta dúvida, diante dos fatos, de que a face autoritária e violenta do regime se consolidou também em torno do controle da sexualidade da população a partir da reafirmação da heteronormatividade sob signos revolucionários, como estratégia política e forma de conter mudanças reais imprevisíveis. A organização moral e sexual reatualizou hierarquias dentro de um sistema excludente das sexualidades não normativas que ganhavam projeção. A sexualidade é um campo de exercício de poder em torno do qual são postos limites à esfera da liberdade e se instauram os eternos dilemas entre ordem e desordem na forma como a sociedade se entende. A partir do sexo se criam as exceções, corpos desprovidos de cidadania, portanto, à margem do direito e que habita, por essa razão, o campo de concentração em suas diferentes manifestações. ${ }^{23}$ Arenas revela de forma subliminar que

\footnotetext{
${ }^{23} \mathrm{O}$ fenômeno dos campos de concentração não tem seu único modelo e fundamento na experiência nazista alemã, pois não se restringe a uma ideologia, e nem encontra necessariamente sua finalidade no extermínio dos prisioneiros. De acordo com o filósofo italiano Giórgio Agamben, o campo é um paradigma do Estado moderno, no qual a vida entra para os cálculos do poder e a política se torna, então, biopolítica (termo retirado de Michel Foucault), ou seja, o ato de "dar forma à vida de um povo". A formação das nações modernas traz em seu cerne, numa complexa relação de fatores, a formação padronizada da existência que acaba por delimitar aquele que está fora e aquele que está dentro das noções de cidadania e de vida que merece ser vivida. Para Agamben, "uma das características essenciais da biopolítica moderna (que chegará no nosso século $[\mathrm{XX}]$ à exasperação) é a sua necessidade de redefinir continuamente, na vida, o limiar que articula e separa aquilo que está dentro daquilo que está fora" (AGAMBEN, 2010, p. 119). De maneira que interessa saber sob quais mecanismos, em diferentes experiências (bio)políticas da modernidade, promove-se tal ordenamento normativo da vida que produz as exceções que habitam o campo. O campo é onde atua o Estado de Exceção, em que os direitos são suspensos e a violência é imposta aos indivíduos excluídos sem que se cometa nenhum delito. Curiosamente, Agamben informa que possivelmente Cuba teve a primeira aparição dos campos de concentração, criados pelos espanhóis em 1896 para reprimir a insurreição da população da colônia (AGAMBEN, 2010, p. 162). O campo, portanto,
} 
somente quando as categorias sexuais fixas que pesam sobre os corpos, mentes e desejos forem reconhecidas no tempo e abolidas, é que se estará mais próximo da liberdade e igualdade no movimento de transformação social, impedindo o passado de construir o futuro.

\section{Referências}

AGAMBEN, Giorgio. Homo Sacer: o poder soberano e a vida nua I. Belo Horizonte: Editora UFMG, 2010.

ARENAS, Reinaldo. El mundo alucinante: (Una novela de aventuras). Madrid, España: Letras Hispánicas, 2017. .. A velha Rosa. Trad. Silvia Costa. Rio de Janeiro: Record, 1996.

ARENAS, Reinaldo. Antes que anoiteça. Rio de Janeiro: Record, 1995.

ARENAS, Reinaldo. Arturo, la estrella más brillante. Barcelona: Montesinos, 1984.

AYERBE, Luis Fernando. A Revolução Cubana. São Paulo: Editora UNESP, 2004.

BANDEIRA, Alberto Moniz. De Martí a Fidel: a Revolução Cubana e a América Latina. Rio de Janeiro: Civilização Brasileira, 1998.

BARRETO, Teresa Cristófani. A libélula, a pitonisa. Revolução, homossexualismo e literatura em Virgílio Piñera. São Paulo: Iluminuras/Fapesp, 1996.

BEJEL, Emilio. Cuerpos peligrosos en una nación de héroes. La Habana: Revista Encuentro de la Cultura Cubana, 41/42, verano/otoño de 2006. p. 76-82 Disponível em: https://www.cubaencuentro.com/revista/content/download/46034/399715/version/2/file/4142e b76.pdf. Acesso em: 25 jul. 2021.

BUTLER, Judith. Problemas de gênero: feminismo e subversão da identidade. $6^{\circ}$ ed. Rio de Janeiro: Civilização Brasileira, 2013.

CANDIANO, Leonardo Martín. Escritores en la Revolución Cubana. Articulaciones entre literatura y política en los años sesenta (1964-1966). Páginas - Revista Digital de la Escuela de Historia, Universidad Nacional de Rosario, año 13, n 33 Septiembre - Diciembre, 2021.

não se refere a uma prática, a um método de tortura ou ao extermínio, mas a uma lógica do poder na produção da vida política. 
Disponível em: https://revistapaginas.unr.edu.ar/index.php/RevPaginas/article/view/549/667. Acesso em: 29 out. 2021.

CARVALHO, Carlos Eduardo (Ed.). Cuba. In.: Socialismo em debate: 1917-1987. São Paulo: Instituto Cojimar, 1988, p. 112-178.

CASTRO, Fidel. Discurso pronunciado por El Comandante Fidel Castro Ruz, Primer Ministro del Gobierno Revolucionario de Cuba, en la clausura del acto para conmemorar el VI aniversario del Asalto al Palacio Presidencial, celebrado en la escalinata de la Universidad de La Habana, el 13 de Marzo de 1963. Disponível em: http://www.cuba.cu/gobierno/discursos/1963/esp/f130363e.html. Acesso em 26 jul. 2021.

CHOMSKY, Aviva. História da Revolução Cubana. São Paulo: Veneta, 2015.

COSTA, Jurandir Freire. Introdução. In.: COSTA, Jurandir Freire. A inocência e o vício: estudos sobre o homoerotismo. Rio de Janeiro: Relume-Dumará, 1992. p. 13-40.

FERNANDES, Florestan. Da guerrilha ao socialismo: a revolução cubana. São Paulo: Expressão Popular, 2007.

FOUCAULT, M. História da Sexualidade I: a vontade de saber. Rio de Janeiro: Edições Graal, 1988.

GUEVARA, Ernesto. Textos políticos. São Paulo: Centro Editorial Latino Americano, 1980. $127 \mathrm{p}$.

HILB, Claudia. Silêncio, Cuba. A esquerda democrática diante do regime da Revolução Cubana. São Paulo: Paz e Terra, 2010.

HIRATA, Helena. Gênero, classe e raça: interseccionalidade e consubstancialidade das relações sociais. Tempo Social, revista de sociologia da USP, v.26, n.1, 2014. p. 61-73.

HOBSBAWM, Eric. Nações e nacionalismo desde 1780. Rio de Janeiro: Paz e Terra, 2002.

HOBSBAWM, Eric. Revolução cultural. In.: Era dos extremos: o breve século XX: 1914-1991. São Paulo, SP: Companhia das Letras, 1995. p. 314-336.

KURI, Ariel Rodríguez. O lado escuro da lua. O momento conservador em 1968. In.: ROLLEMBERG, Denise; QUADRAT, Samantha (orgs.). A construção social dos regimes autoritários: Brasil e América Latina, vol. II.. Rio de Janeiro: Civilização Brasileira, 2010. p. 471-519.

LAMRANI, Salim. Sobre homofobia, Fidel Castro sempre assumiu responsabilidades, diz Mariela Castro. Opera Mundi, 02/02/2013. Disponível em: 
https://operamundi.uol.com.br/politica-e-economia/26925/sobre-homofobia-fidel-sempre-assu miu-responsabilidades-diz-mariela-castro. Acesso em: 09 abr. 2021.

MADERO, Abel Sierra. "El trabajo os hará hombres": Masculinización nacional, trabajo forzado y control social em Cuba durante los años sessenta. Cuban Studies, vol. 44, 2016, p. 309-349.

MADERO, Abel Sierra. Del otro lado del espejo: La sexualidad en la construcción de la nación cubana. Fondo Editorial Casa de las Américas, 2006.

MADERO, Abel Sierra. Sexualidades disidentes en el siglo XIX en Cuba. E.I.A.L., v. 16, n. 1, 2005. p 67-94.

NEGRÓN-MUNTANER, Frances. "Mariconerías de Estado": Mariela Castro, los homosexuales y la política cubana. Nueva Sociedad, n. 218, 2008. p. 163-179.

MISKOLCI, Richard. $O$ desejo da nação: masculinidade e branquitude no Brasil de fins do XIX. São Paulo: Annablume, 2013.

MISKULIN, Sílvia Cesar. Os intelectuais cubanos e a política cultural da Revolução (1961-1975). São Paulo: Alameda, 2009.

MISKULIN, Sílvia Cesar. Cultura ilhada: imprensa e revolução cubana, 1959-1961. São Paulo: Xamã, 2003.

PESAVENTO, Sandra Jatahy. História \& Literatura: uma velha-nova história. In.: COSTA, Cléria Botelho da; MACHADO, Maria Clara Tomaz (orgs.). Literatura e História: identidades e fronteiras. Uberlândia: EDUFU, 2006. p. 11-28.

PRADO, Maria Lígia Coelho. A Participação das Mulheres nas Luta pela Independência Política da América Latina. In.: . América Latina no século XIX: Tramas, Telas e Textos. São Paulo: Editora da Universidade de São Paulo, 2004. p. 29-52.

PRATT, Mary Louise. Mulher, literatura e irmandade nacional. In.: HOLLANDA, Heloisa Buarque de (org.). Tendências e impasses - o feminismo como crítica da cultura. Rio de Janeiro: Rocco, 1994. p. 127-157.

REIS, Daniel Aarão. A revolução e o socialismo em Cuba: ditadura revolucionária e construção do consenso. In.: ROLLEMBERG, Denise; QUADRAT, Samantha (orgs.). $A$ construção social dos regimes autoritários: Brasil e América Latina, vol. II. Rio de Janeiro: Civilização Brasileira, 2010. p. 363-392.

RESOLUÇÕES do Primeiro Congresso Nacional de Educação e Cultura, São Paulo: Livramento, 1980. 
ROBAINA, Tomás Fernández. Los homosexuales y la Revolución. La Habana: Revista Encuentro de la Cultura Cubana, 37/38, verano/otoño de 2005. Disponível em: https://www.cubaencuentro.com/revista/revista-encuentro/archivo/37-38-verano-otono-de-200 5/los-homosexuales-y-la-revolucion-28499. Acesso em: 13 abr. 2021.

ROJAS, Rafael. Anatomia do entusiasmo: cultura e revolução em Cuba (1959-1971). Tempo Social, v. 19, n. 1, 2007. Disponível em: https://www.revistas.usp.br/ts/article/view/12535. Acesso em 13 abr. 2021.

ROLLEMBERG, Denise; QUADRAT, Samantha Viz. Apresentação: Memória, história e autoritarismos. In.: ROLLEMBERG, Denise. QUADRAT, Samantha Viz. A construção social dos regimes autoritários: Brasil e América Latina, vol. II.. Rio de Janeiro: Civilização Brasileira, 2010. p. 11-32.

SADDI, Rafael. A dominação carismática de Fidel Castro (1952-1960). (Dissertação de Mestrado) - Universidade Federal de Goiás, Faculdade de Ciências Humanas e Filosofia, Mestrado de História, Goiânia, 2004, 119 p.

SADDI, Rafael. O ascetismo revolucionário do Movimento 26 de Julho: o sacrifício e o corpo na Revolução Cubana (1952 a 1958). Tese (Doutorado) - Universidade Federal de Goiás, Faculdade de História, Goiânia, 2009. 209 p.

SADER, Emir. A revolução cubana. São Paulo: Urgente, 1992.

SAER, Juan José. O conceito de ficção. Revista FronteiraZ, São Paulo, n. 8, 2012.

SEVCENKO, Nicolau. Literatura como missão: tensões sociais e criação cultural na Primeira República. São Paulo: Companhia das Letras, 2003.

STOPPINO, Mario. Autoritarismo. In: BOBBIO, Norberto; MATTEUCCI, Nicola Matteucci; PASQUINO, Gianfranco Pasquino. Dicionário de Política I. Trad. Carmen C, Varriale et al Brasília: Editora Universidade de Brasília, 11ª ed., 1998.

WASSERMAN, Claudia. Historiografia sobre a revolução cubana no Brasil. Universidad del Atlántico, Historia Caribe, Barranquilla (Col.). n. 12, p. 57-76, 2007.

YOUNG, Allen. Los gays bajo la revolución cubana. Madrid: Editor Playor, 1984. 